05

\title{
Неупругость и наноструктурная дислокационная деформация сплава алюминия с кремнием с супермодифицированной эвтектической структурой
}

\author{
(C) С.П. Никаноров, Б.К. Кардашев, В.Н. Осипов, В.В. Каминский, Н.В. Шаренкова \\ Физико-технический институт им. А.Ф. Иофрфе РАН, \\ 194021 Санкт-Петербург, Россия \\ e-mail: s.nikanorov@mail.ioffe.ru
}

Поступило в Редакцию 28 февраля 2019 г.

В окончательной редакции 28 февраля 2019 г.

Принято к публикации 11 марта 2019 г.

\begin{abstract}
Исследованы модуль Юнга и логарифмический декремент колебаний на частоте $\sim 100 \mathrm{kHz}$, а также размер субзерен и остаточные напряжения в сплаве алюминия с $15 \mathrm{wt} . \%$ кремния, модифицированном стронцием. Сплав был получен при скорости затвердевания $1 \mathrm{~mm} / \mathrm{s}$ в смещенной эвтектической точке. Получена и проанализирована зависимость неупругой дислокационной деформации от приложенного колебательного напряжения. Влияние модификации стронцием на диаграмму микродеформирования объясняется процессом превращения пластинчато-волокнистой структуры эвтектического кремния в супертонковолокнистую.
\end{abstract}

Ключевые слова: сплавы Al, модифицирование, наноструктура, пластичность.

DOI: $10.21883 / J T F .2019 .08 .47894 .72-19$

Литые сплавы алюминия с кремнием имеют широкое применение конструкционного назначения в строительстве зданий и автомобилей, в морской и авиа-индустрии, a также в качестве частей и деталей автомобильных двигателей, дизельных и внутреннего сгорания. Основанием для этого служит их высокая удельная прочность по отношению к весу, высокая теплопроводность, высокое сопротивление коррозии и износостойкость при низком коэффициенте теплового расширения. В настоящее время ведутся интенсивные исследования влияния разных химических элементов на микроструктуру эвтектических $(11-12.5$ wt.\% Si) и заэвтектических сплавов. Уменьшение размеров зерна приводит к увеличению прочности и непредсказуемому в ряде случаев влиянию на другие свойства.

Известно, что значительное увеличение скорости затвердевания вызывает снижение размера зерна микроструктуры, но также и заметное увеличение пористости. В работе [1] было показано, что увеличение скорости затвердевания приводит к одновременному смещению эвтектической точки сплава в сторону увеличения содержания кремния и к соответствующему этой точке увеличению максимальной временной прочности на растяжение. В [2] при умеренно повышенной скорости $(1 \mathrm{~mm} / \mathrm{s})$ направленного затвердевания был получен сплав Al-15 wt.\% Si в смещенной в сторону более высоких концентраций эвтектической точке. Сплав имел тонкую волокнистую эвтектическую структуру без первичных кристаллов кремния, соответствующую 5 рейтингу структуры Американского литейного общества AFS [3], и повышенную предельную прочность. После добавки 0.01 wt.\% Sr была получена супермодифицированная эвтектическая структура, соответствующая 6 рейтингу системы AFS, с высокой прочностью и рекордно высокой пластичностью. Однако другие физико-механические свойства этого необычного литого сплава заэвтектического состава, имеющего полностью эвтектическую структуру без первичного кремния, от которых зависят потенциальные области его практического применения, не были исследованы.

В настоящей работе исследуются микроструктура, остаточные микронапряжения, дислокационные дефект модуля упругости и внутреннее трение, а также диаграмма неупругого деформирования сплава $\mathrm{Al}-15$ wt.\% $\mathrm{Si}-0.01$ wt.\% $\mathrm{Sr}$ с супермодифицированной структурой. Сплав был получен направленной кристаллизацией при вытягивании из расплава ленты $1000 \times 15 \times 3 \mathrm{~mm}$ через формирующее устройство с воздушным охлаждением по способу Степанова [1]. Температура расплава была $660^{\circ} \mathrm{C}$, скорость вытягивания $1 \mathrm{~mm} / \mathrm{s}$. Градиент температуры был около $12 \mathrm{~K} / \mathrm{mm}$. Чистота исходных материалов была 99.9 wt.\% для $\mathrm{Al}$ и $\mathrm{Sr}, 99.8 \mathrm{wt} \%$ для $\mathrm{Si}$. Образцы для исследований в виде стержней длиной около $27 \mathrm{~mm}$ с поперечным сечением $6 \mathrm{~mm}^{2}$ вырезались электроискровым методом из закристаллизованной ленты.

Исследуемый сплав состоял из $\alpha$-Al твердого раствора кремния в алюминии и кристаллов кремния. Рентгеноструктурный анализ показал, что $\alpha$-Al имеет субзеренную структуру. Размер субзерна $\alpha$-Al твердого раствора оценивался по размерам областей когерентного рассеяния (ОКР) рентгеновского излучения. Рентгеноструктурный анализ проводился гониодифрактометрическим методом на основе дифрактограмм $(\theta-2 \theta$ сканирование), полученных на дифрактометре ДРОН-2 в $K_{\alpha}$-излучении медного анода. Размер ОКР определялся по ширине 
Размер областей когерентного рассеяния $\alpha$-Al твердого раствоpa $L$, остаточная деформация $\varepsilon_{0}$, модуль Юнга $E$ и остаточные напряжения $\sigma_{0}$

\begin{tabular}{c|c|c|c|c|c}
\hline $\begin{array}{c}\text { Состав } \\
\text { сплава }\end{array}$ & Состояние & $L \mathrm{~mm}$ & $\varepsilon_{0}, 10^{-3}$ & $E, \mathrm{GPa}$ & $\begin{array}{c}\sigma_{0} \approx E \varepsilon, \\
\mathrm{MPa}\end{array}$ \\
\hline $\begin{array}{c}\text { Al-15wt.\% } \mathrm{Si}- \\
\text { 0.01wt.\%Sr }\end{array}$ & $\begin{array}{c}\text { исходное } \\
\text { изгле }\end{array}$ & $93 \pm 20$ & $0.9 \pm 0.1$ & 79.7 & 71 \\
\hline $\mathrm{Al}-15 \mathrm{wt} \% \mathrm{Si}$ & исходное & $80 \pm 10$ & $0.8 \pm 0.1$ & 80.4 & 64
\end{tabular}

пика $B$ на малых углах отражения от плоскостей с индексами Миллера $h k l$ на половине высоты пика по формуле Селякова-Шеррера [4]:

$$
L_{h k l}=\lambda / B \cos \theta_{h k l},
$$

где $\lambda$ - длина волны рентгеновского излучения. Метод также позволял определять микронапряжения II рода по остаточным деформациям межплоскостного расстояния, которые определялись по ширине пика на больших углах отражения:

$$
\varepsilon_{0}=\Delta d / d=B / 4 \operatorname{tg} \theta_{h k l},
$$

где $d-$ межплоскостное расстояние. Относительные погрешности для $L \approx 10^{2} \mathrm{~nm}$ и для $\varepsilon_{0}$ были не более $20 \%$.

Результаты рентгеновских измерений размеров областей когерентного рассеяния в средней части образца до и после предварительной деформации показаны в таблице. Различие между средними размерами субзерна $\alpha$-Al твердого раствора немодифицированного сплава и сплава, модифицированного стронцием меньше пределов погрешности измерений. Оба сплава имеют наноструктурированную $\alpha-\mathrm{Al}$ составляющую эвтектики. В таблице представлены также данные по величинам остаточной деформации $\varepsilon_{0}$, модулю Юнга $E$ и остаточным напряжениям $\sigma_{0}$.

Модуль Юнга $E$ и логарифмический декремент $\delta$ (внутреннее трение) образцов измерялись методом составного пьезоэлектрического вибратора с частотой продольных колебаний около $100 \mathrm{kHz}$ [5]. Амплитуда колебательной деформации $\varepsilon$ изменялась в пределах двух порядков от $\sim 1.2 \cdot 10^{-6}$ до $2 \cdot 10^{-4}$, что позволяло выходить в нелинейную область амплитудно-зависимого внутреннего трения. Ошибка определения $E$ материала с учетом разброса данных на разных образцах была около $1 \%$. Относительная ошибка измерения $E$ на одном образце при изучении влияния амплитуды колебаний не превышала $10^{-3 \%}$. Относительная ошибка измерений $\delta$ была не более $10 \%$.

Зависимость модуля Юнга и логарифмического декремента от амплитуды колебательной деформации $\varepsilon$ для исходного (недеформированного) образца сплава $\mathrm{Al}-15$ wt.\% Si-0.01 wt.\% Sr показана на рис. 1 (кривая 1). Согласно теории амплитудно-зависимого внутреннего трения [6], неупругая деформация (нелинейная, но без остаточного смещения) и необходимые для этого затраты энергии определяются при частоте колебаний около $10^{5} \mathrm{~Hz}$, главным образом взаимодействием движущихся дислокаций с окружающими точечными дефектами. Зависимость $E$ и $\delta$ от $\varepsilon$ значительно возрастает после пластического изгиба (кривая 2) за счет введения в образец свежих, закрепленных небольшим количеством точечных дефектов дислокаций. Однако, как видно из рисунка, модуль Юнга образца, измеряемый при малых амплитудах колебательной деформации около $10^{-6}$, не уменьшается после деформации, как требует теория [6], а немного возрастает, примерно на $0.3 \%$. Этот эффект связывают с ростом остаточных внутренних напряжений [7] за счет влияния на измеряемый модуль упругих постоянных высших порядков. Результаты рентгеноструктурного анализа (см. таблицу) не противоречат этому. Уже в исходных образцах имеется остаточная деформация и соответствующий ей уровень напряжений - около $71 \mathrm{MPa}$. Остаточные напряжения после изгиба в вогнутой, сжатой стороне стержня в среднем возрастают на $17 \%$, до $\sim 83 \mathrm{MPa}$. При этом размер субзерен уменьшается в два раза, до $46 \mathrm{~nm}$.

Характер изменений зависимостей $E(\varepsilon)$ и $\delta(\varepsilon)$ под влиянием пластического изгиба, показанный на рис. 1 , оказался качественно подобным тому, что наблюдался при исследовании немодифицированного сплава

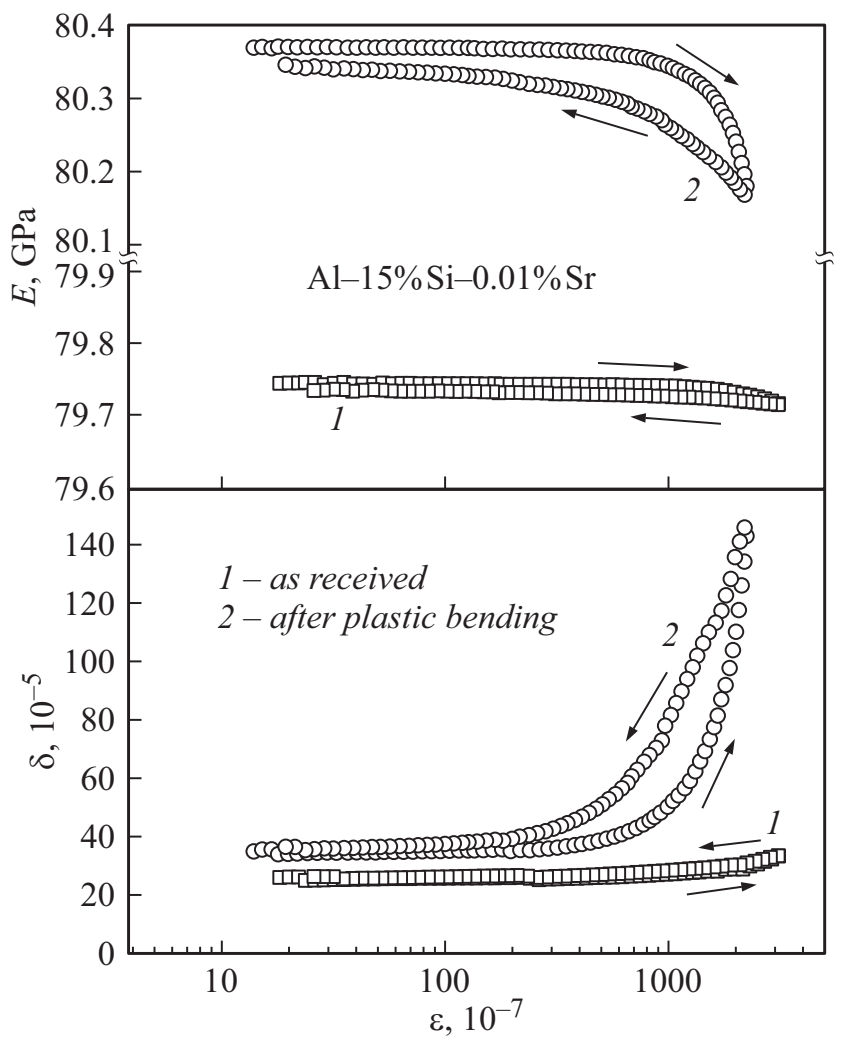

Рис. 1. Амплитудные зависимости модуля Юнга $E$ и декремента $\delta$ сплава Al-15wt.\% Si-0.01 wt.\% Sr до (1) и после (2) пластической деформации изгибом. 


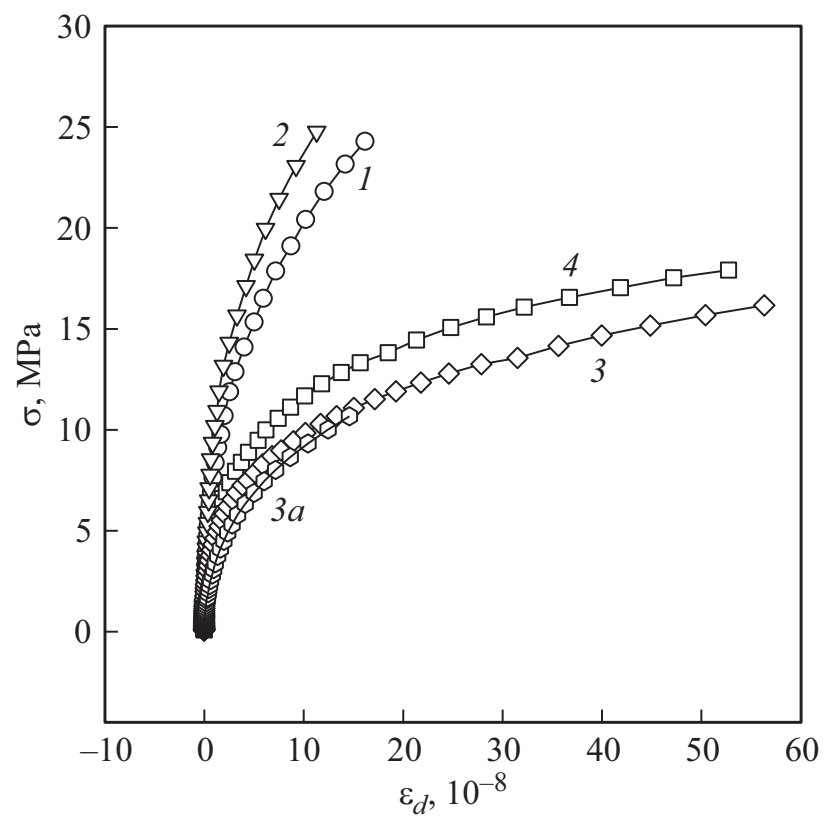

Pис. 2. Диаграммы микропластического деформирования сплавов Al-15 wt.\% Si $(1,3,3, a) \quad$ и $\quad \mathrm{Al}-15 \mathrm{wt} . \% \mathrm{Si}-$ 0.01 wt.\% $\mathrm{Sr}(2,4)$ до $(1,2)$ и после $(3,3 a, 4)$ пластической деформации изгибом.

Al-15 wt.\% Si: $E$ и $\delta$ не зависят от $\varepsilon$ до амплитуды деформации около $2 \cdot 10^{-5}$ и далее быстро изменяются с увеличением $\varepsilon$ (модуль падает, а декремент растет).

Из экспериментальных кривых $E(\varepsilon)$ можно построить зависимость колебательного напряжения, действующего на образец, $\sigma=E \varepsilon$ от амплитуды колебательной неупругой дислокационной деформации $\varepsilon_{d}=(\Delta E / E) \varepsilon$, где $\Delta E=E_{\varepsilon}-E$, а $E_{\varepsilon}-$ модуль Юнга, измеряемый при амплитуде колебательной упругой деформации $\varepsilon$. Величину $\Delta E / E$ называют дислокационным дефектом модуля Юнга.

Зависимости амплитуды колебательного напряжения $\sigma$ от амплитуды дислокационной деформации $\varepsilon_{d}$ для немодифицированного (Al-15 wt.\% $\mathrm{Si}$ ) и модифицированного стронцием (Al-15 wt.\% Si- $0.01 \% \mathrm{Sr}$ ) сплавов до и после предварительного пластического изгиба показаны на рис. 2. Они позволяют выявить особенности начальной стадии неупругого деформирования материала, предшествующего развитой пластической деформации. На рис. 2 видно, что деформирование образцов обоих сплавов приводит к уменьшению напряжения микроскопического течения при заданной деформации (кривые $2 \rightarrow 4,1 \rightarrow 3)$. Это объясняется увеличением плотности дислокаций в испытуемом образце. Нужно отметить, что напряжение $\sigma$-образцов модифицированного стронцием сплава (кривая 2) выше, чем сплава без стронция (1) при одной и той же деформации.

Ранее [3] было показано, что модификация стронцием приводит к более тонкой волокнистой эвтектике и повышает прочность и пластичность заэвтектических сплавов алюминия с кремнием. Авторы [2] предполагали, что модификация стронцием расплава заэвтектического состава $\mathrm{Al}-15 \mathrm{wt} . \% \mathrm{Si}$, затвердевающего в квазиэвтектической точке при скорости $1 \mathrm{~mm} / \mathrm{s}$, будет более эффективной, чем традиционных сплавов. Это предположение оправдалось. Модификация этого сплава с тонкой пластинчато-волокнистой структурой привела к образованию тонкой, неразрешимой в оптическом микроскопе структуры (см. рис. 1 в [2]). На этом рисунке видно, что срезы пластин и волокон эвтектического кремния в виде изогнутых линий и отдельных точек микронного масштаба в сплаве $\mathrm{Al}-15 \mathrm{wt} . \% \mathrm{Si}$ (рис. 1,a) превратились в субмикронные линии и точки в модифицированном Al-15 wt.\% Si-0.01\% Sr сплаве (рис. 1, $b$ ). $\mathrm{B}$ то же время модификации структуры $\alpha$-Al в эвтектике не наблюдается. Из таблицы видно, средний размер субзерен $\alpha$-Al твердого раствора после модификации стронцием практически не изменился.

Согласно [8], уменьшение среднего расстояния между частицами эвтектического кремния $L$ при превращении пластинчатой (чешуйчатой) структуры кремния в волокнистую структуру приводит к росту напряжения течения и увеличению прочности при растяжении пропорционально $L^{-2}$. Это связано с увеличением сопротивления движущимся дислокациям. Можно считать, что увеличение напряжений микропластического течения при колебательном деформировании после модификации стронцием также вызвано уменьшением $L$ при превращении пластинчато-волокнистой структуры эвтектического кремния в супертонкую волокнистую.

На рис. 2 приведена также зависимость напряжений течения $\sigma$ от неупругой дислокационной деформации $\varepsilon_{d}$ для образца сплава Al-15 wt.\% Si, полученного в 2008 г. $($ кривая $3, a)$ по той же технологии и из тех же исходных материалов, что и в настоящей работе. Совпадение зависимостей 3 и $3, a$ свидетельствует об отсутствии при длительном хранении заметного старения сплава, полученного в смещенной эвтектической точке.

Таким образом, впервые показано, что $\alpha$-Al, составляющая сплава $\mathrm{Al}-15 \mathrm{wt} . \% \mathrm{Si}$, полученного в смещенной эвтектической точке, наноструктурирована с размером субзерна около $80 \mathrm{~nm}$. Акустическое исследование амплитудной зависимости модуля Юнга позволило восстановить диаграмму колебательной микропластической деформации при растяжении, предшествующей макродеформации. Ее изменение при модифицировании сплава стронцием подобно тому, что наблюдается при макропластической деформации. Характер этого изменения может быть объяснен уменьшением среднего расстояния между частицами эвтектического кремния при превращении пластинчато-волокнистой структуры эвтектического кремния в супертонкую волокнистую.

\section{Конфликт интересов}

Авторы заявляют, что у них нет конфликта интересов. 


\section{Список литературы}

[1] Никаноров С.П., Деркаченко Л.И., Кардашев Б.К., Корчунов Б.Н., Осипов В.Н., Шиейзман В.В. // ФТТ. 2013. Т. 55. Вып. 6. С. 1119-1125. [Nikanorov S.P., Derkachenko L.I., Kardashev B.K., Korchunov B.N., Osipov V.N., Shpeizman V.V. // Phys. Solid State. 2013. Vol. 55. N 6. P. 1207-1213.]

[2] Аверкин А.И., Корчунов Б.Н., Никаноров С.П., Осипов В.Н. // Письма в ЖТФ. 2016. Т. 42. Вып. 4. С. 67-73. [Averkin A.I., Korchunov B.N., Nikanorov S.P., Osipov V.N. // Tech. Phys. Lett. 2016. Vol. 42. N 2. P. 200-203.]

[3] Sigworth G.K. // International Journal of Metalcasting. 2008. Vol. 2. N 2. P. 19-41.

[4] Kaminski V., Sharenkova N. // Materials Science Nonequilibrium Phase Transformations. 2018. Vol. 4. N 4. P. $12-113$.

[5] Marx J. // Rev. Scient. Instr. 1951. Vol. 22. N 7. P. 503-508.

[6] Gremaud G. // Mater. Sci. Forum. 2001. Vol. 366-368. P. $178-246$.

[7] Chernov V.M., Kardashev B.K., Krjukova L.M., Mamaev L.I., Plaksin O.A., Rusanov A.E., Solonin M.I., Stepanov V.A., Votinov S.N., Zavialsky L.P. // J. Nucl. Mater. 1998. Vol. 257. P. 263-273.

[8] Hosch T., Napolitano R.E. // Mater. Sci. Eng. A. 2010. Vol. 528. N 1. P. 226-232. 